\title{
Analysis and removal of emerging contaminants in wastewater and drinking water
}

Mira Petrović*, Susana Gonzalez, Damià Barceló

Department of Environmental Chemistry, IIQAB-CSIC, c/Jordi Girona 18-26, 08034 Barcelona, Spain

* Corresponding author: tel.: +34 93400 6172, fax: +34 932045904 e-mail: mpeqam@cid.csic.es

\section{Abstract}


The occurrence of trace organic contaminants in wastewaters, their behaviour during wastewater treatment and drinking water production are the key issues in relation to the reuse of water resources. Elimination of different classes of emerging contaminants, such as surfactant degradates, pharmaceuticals and polar pesticides in wastewater treatment plants (WWTP) was found to be rather low and consequently sewage effluents are one of the main sources of these compounds and their recalcitrant metabolites.

This paper reviews the state-of-the-art in the analysis of several groups of emerging contaminants (acidic pharmaceuticals, antibacterial agents, acidic pesticides and surfactant metabolites) in wastewaters. Their elimination in WWTP applying conventional activated sludge treatment and advanced treatment processes, such as membrane bioreactors (MBR) and advanced oxidation (AOP), as well as the elimination during drinking water production are discussed.

\section{Keywords}

Acidic pharmaceuticals; Acidic pesticides; Advanced treatment; Emerging contaminants; Surfactant degradates, Wastewater treatment 


\section{Introduction}

Until the beginning of the 1990' non-polar hazardous compounds, i. e. persistent organic pollutants (POP) and heavy metals, were in the focus of interest and awareness as priority pollutants, and consequently were part of intensive monitoring programs. Today, these compounds are less relevant for the industrialized countries since a drastic reduction of emission has been achieved due to the adoption of appropriate measures and elimination of the dominant pollution sources.

However, the emission of so-called "emerging" or "new" unregulated contaminants has emerged as an environmental problem and there is a widespread consensus that this kind of contamination may require legislative intervention. This group is mainly composed of products used in large quantities in everyday life, such as human and veterinary pharmaceuticals, personal care products, surfactants and surfactants' residues, plasticizers and different industrial additives. The characteristic of these contaminants is that they do not need to be persistent in the environment to cause negative effect since their high transformation/removal rates can be compensated by their continuous introduction into environment. One of the main sources of emerging contaminants are untreated urban wastewaters and wastewater treatment plant (WWTP) effluents. (Fig. 1). Most current WWTP are not designed to treat this type of substances and the high portion of emerging compounds and their metabolites can escape elimination in the WWTP and enter the aquatic environment via sewage effluents.

The partial or complete closing of water cycles is an essential part of sustainable water resources management and the increasing scarcity of pristine waters for drinking water supply and increasing consume of water by industry and agriculture should be countered by the efficient and rational utilisation of resources. One of the options is 
increasing reuse of effluents for various purposes, especially in industrial and agro/food production activities. However, due to high cost of end-of-pipe approach (drinking water treatment) the future of indirect potable reuse requires an efficient treatment of wastewaters prior to their discharge. Thus, the occurrence of trace organic contaminants in wastewaters, their behaviour during wastewater treatment and drinking water production are the key issues that require further study.

Many believe that of all emerging contaminants, antibiotics are the biggest concern, since their emission in the environment can result in an increased occurrence of resistant bacteria in the environment [1]. However, other emerging compounds, especially polar one, such as acidic pharmaceuticals, acidic pesticides and acidic metabolites of non-ionic surfactants also deserve particular attention. Due to their physico-chemical properties (high water solubility and often poor degradability) they are able to penetrate through all natural filtration steps and man-made treatments, thus presenting a potential risk for drinking water supply $[2,3]$.

Different classes of emerging contaminants, mainly surfactant degradates, pharmaceuticals and personal care products (PPCP) and polar pesticides were found to have rather low elimination rates and have been detected in WWTP effluents and in the receiving surface waters. However, for most of emerging contaminants, occurrence, risk assessment and ecotoxicological data are not available and it is difficult to predict their fate in the aquatic environment. Partially, the reason for this is a lack of analytical methods for their determination at trace concentrations. Analysis of emerging contaminants is a real analytical challenge, not only because of the diversity of chemical properties of these compounds, but also because of generally low concentrations (usually part per billion or part per trillion levels) and the complexity of matrices. 
This paper reviews the state-of-the-art in the analysis of several groups of emerging contaminants (acidic pharmaceuticals, antibacterial agents, acidic pesticides and surfactant metabolites) in wastewaters. Various aspects of current LC-MS-(MS) and GC-MS methodology, including sample preparation, are discussed.

It also gives a survey of their elimination in WWTP by activated sludge treatment (AST) and applying advanced treatment processes, such as membrane bioreactors (MBR) and advanced oxidation (AOP). Additionally, the elimination in treatment processes at drinking water treatment plants is discussed.

\section{Analysis of emerging contaminants in wastewaters}

One of the major limitations in the analysis of emerging contaminants remains to be the lack of analytical methods for quantification of low concentrations. The prerequisite for proper risk assessment and monitoring of waste, surface and drinking water quality is the availability of a multiresidual analytical method that permits measurement at the low (or even below) ng/L level. However, the fact that these compounds are not on the regulatory lists as environmental pollutants resulted in comparatively little attention received. Consequently, analytical methodology for different groups of emerging contaminants is evolving and the number of methods described in the literature for the determination of emerging contaminants has grown considerably. Still, the analysis of this group of contaminants requires further improvements in terms of sensitivity and selectivity, especially for very complex matrices, such as wastewater. 


\subsection{Acidic pharmaceuticals}

Different analytical methods, mainly based on LC-MS and GC-MS, repectively in combination with either polymer or $\mathrm{C}_{18}$-based solid phase extraction (SPE), are being developed for the analysis of pharmaceutical compounds. However, most methods are tailored for neutral compounds (e.g. antibiotics) and less complex matrices (surface and groundwater), while only a limited number of paper describes procedures applicable to the analysis of polar drugs in wastewater samples. A survey of analytical methods for the quantification of regularly used polar pharmaceuticals in wastewater matrices is given in Table 1.

A typical analytical method includes the use of octadecylsilica, polymeric, or hydrophilic-lipophilic balanced (HBL) supports for off-line SPE of water samples, with either disks or, most frequently, cartridges at low $\mathrm{pH}$ (typically $\mathrm{pH}=2$ ).

Separation technique used includes both GC and LC, while for detection, MS has been the technique most widely employed. Due to low volatility of polar pharmaceuticals GC-MS analysis requires additional derivatization step, which makes the sample preparation laborious and time consuming, and also increases the possibility of contamination and errors. Moreover, some compounds are thermolabile and decompose during GC analysis (e.g. carbamazepine forms iminostilben as degradation product) [4].

Consequently, LC-MS and LC-MS-MS are increasingly used. Reviewing principal analytical methods employed in the analysis of pharmaceuticals in aqueous environmental samples Ternes [4] indicated LC-MS-MS as the technique of choice to assay polar pharmaceuticals and their metabolites, however pointed out the difficulty in the enrichment step, as well as the low resolution and the suppression of signals in the electrospray (ESI) interface due to matrix impurities. Farré et al. [5] have compared LC-(ESI)-MS and GC- 
MS (after a derivatization with $\mathrm{BF}_{3}-\mathrm{MeOH}$ ) for the monitoring of some acidic and very polar analgesics (salicylic acid, ketoprofen, naproxen, diclofenac, ibuprofen and gemfibrozil) in surface waters and wastewater samples. Results showed a good correlation between methods expect for the gemfibrozil which derivatization was not completely achieved in some samples.

In general, the limits of detection (LODs) achieved with the LC-MS-(MS) methods were slightly higher than those obtained with the GC-MS methods (see Table 1), however, LC-MS methodology showed advantages in terms of versatility and less complicated sample preparation (no derivatization needed).

Table 2 summarizes the quantitation and qualifier ions used by the various authors for the determination of polar drugs in wastewaters using the selected ion monitoring (SIM) or the multiple reaction monitoring (MRM) mode. The use of triple-quadropole mass spectrometers in LC analysis has substantially increased the selectivity and sensitivity of the determination, resulting in LODs better than those achieved by use of single-quadropole LC-MS. Acidic drugs were usually detected using an ESI interface under negative ionization conditions and deprotonated molecules where chosen as precursor ions. Typical fragmentation pattern obtained with LC-MS-MS showed a loss of $\mathrm{CO}_{2}$ (or loss of the acidic moiety), with a limited number of other products. For example, for diclofenac, ibuprofen and ketoprofen the product ions generated by expulsion of $\mathrm{CO}_{2}$ were the only fragment ions formed.

\subsection{Acidic pesticides}

Chlorinated phenoxy acid herbicides account for the majority of pesticides used worldwide and their presence in environmental waters is well documented. However, their 
behaviour during wastewater treatment was rarely studied. This group of herbicides is characterized by high polarity and thermal lability. For these reasons LC is generally more suitable for their analysis, as the sample pretreatment does not require a time-consuming derivatization step. However, the methods used to determine chlorinated phenoxy acid herbicides are still dominated by GC either with electron capture detector (ECD) or MS detection. The main disadvantage of $\mathrm{GC}$ analysis is that requires prior derivatization step, usually using highly toxic and carcinogenic diazomethane or, less frequently used, acid anhydrides, benzyl halides and alkylchloroformates. The injection-port derivatization with an ion-pair reagent has been successfully applied [6], as well as, in-situ derivatization prior to solid-phase microextraction (SPME) [7].

Alternative methods based on LC-MS have been proposed, using an ESI interface, which is well suited to the determination of easily ionized chlorinated phenoxy acids. Using LC-MS-(MS), phenoxy acid herbicides are detected under negative ionization conditions typically yielding $[\mathrm{M}-\mathrm{H}]^{-}$ion and one abundant fragment formed by the loss of acidic moiety $[8,9]$.

Recently, in-tube SPME followed by LC-MS was applied for the determination of six chlorinated phenoxy acid herbicides [10]. However, method was applied to river water achieving LODs ranging from 5 to $30 \mathrm{ng} / \mathrm{l}$, while more complex wastewater matrix was not tested.

\subsection{Antiseptics}

Several methods have been proposed for the determination of triclosan (5-chloro-2[2,4-dichlorophenoxy] phenol), which is used as an antiseptic agent in a vast array of 
personal care (e.g. toothpaste, acne cream, deodorant, shampoo, toilet soap) and consumer products (children's toys, footwear, kitchen cutting boards).

Methods based on diazomethane derivatization and capillary GC-ECD was applied for their quantification in the wastewater of a slaughterhouse [11], using silica clean up without derivatization and analysis by GC-MS [12] and SPE of acidified wastewater water samples and SFE for lyophilized sludge, respectively followed by derivatization and GCHRMS were recently developed [13].

Recently, a method based on LC-MS was also proposed, achieving a limit of detection of $0.35 \mu \mathrm{g} / \mathrm{L}$ in spiked urban wastewater [14].

\subsection{Alkylphenolic compounds}

The trace analysis of alkylphenol ethoxylates (APEOs) and their acidic metabolites by LC-MS or LC-MS-MS using atmospheric pressure ionization (API) has been recently reviewed by Petrovic et al. $[15,16]$ and the performances of two ionization methods, APCI and ESI, in terms of selectivity and sensitivity toward oligomeric mixtures of APEOs has been discussed. Generally, ESI interface is more often used for the analysis of alkylphenolic compounds due to the higher sensitivity, especially for alkylphenols and carboxylated compounds.

Alkylphenoxy carboxylates (APEC) were detected, in both, the NI and PI mode. In the NI mode, using ESI, APECs give two types of ions, one corresponding to the deprotonated molecule $[\mathrm{M}-\mathrm{H}]^{-}(\mathrm{m} / \mathrm{z} 277,321,263$ and 307 corresponding to nonylphenol carboxylate $\left(\mathrm{NPE}_{1} \mathrm{C}\right)$, nonylphenol ethoxycarboxylate $\left(\mathrm{NPE}_{2} \mathrm{C}\right)$, octylphenol carboxylate $\left(\mathrm{OPE}_{1} \mathrm{C}\right)$, and octylphenol ethoxycarboxylate $\left(\mathrm{OPE}_{2} \mathrm{C}\right)$, respectively) and the other corresponding to deprotonated alkylphenols [17]. The relative abundance of these two ions 
depends on the extraction voltage. In the presence of ammonium acetate and using an APCI under PI conditions $\mathrm{NPE}_{1} \mathrm{C}$ gave $\left[\mathrm{M}+\mathrm{NH}_{4}\right]^{+}$ions at $\mathrm{m} / \mathrm{z} 296$, while $\mathrm{NPE}_{2} \mathrm{C}$, gave $\left[\mathrm{M}+\mathrm{NH}_{4}\right]^{+}$ion at $\mathrm{m} / \mathrm{z} 340[18]$.

LC-ESI-MS was also applied for the analysis of the dicarboxylated breakdown products (carboxylated alkylphenoxy carboxylates; CAPECs) in wastewaters $[19,20]$. However, the identification of these compounds using LC-MS, under conditions giving solely molecular ions, is difficult since $\mathrm{CA}_{n} \mathrm{PE}_{\mathrm{m}} \mathrm{Cs}$ have the same molecular mass as APECs having one ethoxy unit less and a shorter alkyl chain $\left(\mathrm{A}_{\mathrm{n}-1} \mathrm{PE} \mathrm{m}_{\mathrm{m}-1} \mathrm{C}\right)$. Moreover, since some compounds partially co-elute, the unequivocal assignment of the individual fragments can be accomplished only using LC-MS-MS. Typical fragmentation pattern obtained with LC-ESI-MS-MS showed the formation of the carboxy-alkylphenoxy fragment, with an additionally lost $\mathrm{CO}_{2}$, or an acetic acid group, in the case of $\mathrm{CA}_{5} \mathrm{PE}_{1-2} \mathrm{C}$ leading to the fragments of $m / z 149$ and 133 [19].

MS-MS spectra of APECs [19,21,22] shows an intense signal at $\mathrm{m} / \mathrm{z} 219$ (for NPECs) and $m / z 205$ (for OPECs) that is produced after the loss of the carboxylated (ethoxy) moiety, while sequential fragmentation of the alkyl chain resulted in ions $\mathrm{m} / \mathrm{z} 133$ and 147.

To overcome the problem with the low volatility of acidic alkylphenolic compounds different off-line and on-line derivatization protocols, respectively have been developed. Off-line derivatization to corresponding triemethylsilyl ethers, methyl ethers, acetyl esters, pentafluorobenzoyl, or heptafluorobutyl esters, respectively was applied as a common approach in GC-MS analysis. On-line direct GC injection-port derivatization using ion-pair reagents (tetraalkylammonium salts), has been also reported [23]. The most significant ions in GC-(EI)-MS of methylated NPECs were fragments produced by rupture of the benzylic bond in the branched nonyl side-chain [23,24,25]. GC-CI-MS spectra of 
the NPECs with isobutane as reagent gas showed characteristic hydride ion-abstracted fragment ions shifted by $1 \mathrm{Da}$ from those in the corresponding EI mass spectra [22]. Using ammonia as reagent gas intense ammonia-molecular ion adducts of the methyl esters, with little, or no secondary fragmentation were reported for the detection of NPECs [26]. Ions selected were as follows: $m / z$ 246, 310, 354 and 398 for $\mathrm{NPE}_{1} \mathrm{C}, \mathrm{NPE}_{2} \mathrm{C}, \mathrm{NPE}_{3} \mathrm{C}$ and $\mathrm{NPE}_{4} \mathrm{C}$, respectively.

\section{Elimination by activated sludge treatment (AST)}

The present state-of-the-art of wastewater treatment involves treatment by the activated sludge treatment (AST) process proceeded with conventional physico-chemical pre-treatment steps. Table 3. summarizes data on the elimination of emerging contaminants in WWTP.

\subsection{Pharmaceuticals and personal care products}

Daughton and Ternes [1] reviewed the occurrence of over 50 individual PPCPs, or metabolites from more than 10 broad classes of therapeutic agents, or personal care products in environmental samples, mainly in WWTP effluents, surface, and ground waters and much less frequently in drinking waters. Acidic drugs are the major group of PPCPs detected in municipal WWTP and among them bezafibrate, naproxen, and ibuprofen were the most abundant (concentrations up to $4.6 \mu \mathrm{g} / 1$ were detected in German municipal WWTPs). Tixier et al. [27] determined that carbamezapine presented the highest daily load 
from the WWTP into Lake Greifensee (Switzerland), followed by diclofenac, and naproxen. Their elimination during passage through a municipal sewage treatment in most cases was found to be quite low (see table 3), ranging from 35 to $90 \%$ and some compounds, like carbamazepine, exhibit extremely low removal (only 7\%) [28]. Consequently, through sewage effluents they can enter receiving surface waters and thus become a potential risk in the production of drinking water. For example, the clofibric acid, a metabolite of three lipid regulating agents (clofibrate, etofibrate and fenofibrate) has been identified in river and ground water and even in drinking water at concentrations ranging up to $165 \mathrm{ng} / \mathrm{l}[29,30]$.

\subsection{Acidic Pesticides}

Chlorinated phenoxyacids are a kind of compounds widely used in agriculture. This group includes, for example, mecoprop (MCPP), MCPA, 2,4-D, 2,4-DP 2,4,5-T, 2,4-DB. Monitoring of these herbicides is important in surface water because of their potential toxicity towards animals and humans [31], however, these compounds are not only used for agricultural purposes, but also as herbicides on lawns, algicides in paints and coatings or as roof protection agents in flat roof sealings. So, residues of these substances are introduced into the aquatic system through different pathways. For example, in the catchment area of Lake Greifensee (Switzerland) 65\% of the mecoprop originated from WWTPs and the remaining 35\% from diffuse sources [32].

Degradation of acidic pesticides under laboratory conditions is well studied, but there are only few publications dealing with their behaviour in real wastewater treatment processes. Generally, activated sludge treatment was found to be ineffective in removing chlorinated phenoxy acid herbicides from settled sewage. However, under laboratory 
conditions mecoprop proved to be biodegradable (nearly 100\%), however it required long adaptation time (lag-phase) of activated sludge [33]. In real wastewater treatment processes this presents a major difficulty since, like the majority of herbicides, mecoprop is applied only during a short growth period of plants, which means that during this period WWTPs, that contains a non-adapted activated sludge, receive shock-loads of herbicides and consequently these substances are not eliminated.

A long acclimation period (about 4 months) was also observed in a bench-scale study using sequencing batch reactors before 2,4-D biodegradation was established [34]. Afterwards, at steady-state operation, all reactors achieved practically complete removal $(>99 \%)$ of $2,4-\mathrm{D}$.

\subsection{Alkylphenolic surfactants}

Although their environmental acceptability is strongly disputed APEOs are still among the most widely used non-ionic surfactants. Currently, under optimised conditions, more than $90-95 \%$ of surfactants are eliminated by conventional biological wastewater treatment (normally activated sludge treatment). Even if such high elimination rates are achieved, the principal problem is the formation of recalcitrant metabolites out of the parent surfactants. The widespread occurrence of APEO-derived compounds in treated wastewaters and the following disposal of effluents into aquatic system raise concerns about their impact on the environment. Studies have shown that their neutral (alkylphenols and short ethoxy chain ethoxylates) and acidic recalcitrant metabolites (APEC) possess the ability to mimic natural hormones by interacting with the estrogen receptor.

It was estimated that approximately 60 to $65 \%$ of all nonylphenolic compounds introduced to WWTP are discharged into the environment; $19 \%$ in the form of 
carboxylated derivatives, $11 \%$ in the form of lipophilic $\mathrm{NP}_{1} \mathrm{EO}$ and $\mathrm{NP}_{2} \mathrm{EO}, 25 \%$ in the form of NP and $8 \%$ as untransformed NPEOs [35].

However, contrary to the general believing that NPECs are the refractory metabolites, Di Corcia et al. [36] determined that CAPECs are the dominant products of the NPEO biotransformation. By averaging data relative to the treated effluents of five major activated sludge WWTP of Rome (Italy) over 4 months, relative abundances of NPEO ( $n_{\mathrm{EO}}=1$ and 2), NPECs and CAPECs were found to be respectively $10 \pm 2 \%, 24 \pm 5 \%$ and $66 \pm 7 \%$.

The average concentrations of acidic metabolites, NPECs and CAPECs are at low $\mu \mathrm{g} / \mathrm{L}$ range, however high values, up to several tens of hundreds of $\mu \mathrm{g} / \mathrm{L}$, are detected in effluents of WWTP receiving industrial wastewaters, especially from tannery, textile, pulp and paper industry [37].

\section{Elimination by advance wastewater treatment processes}

Although, adopted as the best available technology; biological treatment permits only partial removal of a wide range of emerging contaminants, especially polar ones, which are discharge into the final effluent. Thus, it has become evident that application of more enhanced technologies may be crucial for the fulfilment of the requirements of an indirect potable reuse of municipal and industrial wastewater. In recent years, new technologies are being studied, not only for wastewater treatment but also for drinking water production. Among them membrane treatment, using both biological (membrane bioreactors) and non-biological processes (reversed osmosis, ultrafiltration, nanofiltration), 
and advanced oxidation processes (AOP) are most frequently considered as treatments that may be appropriate to remove trace concentrations of polar emerging contaminants.

\subsection{Membrane processes}

Membrane bioreactor (MBR) technology is considered as the most promising development in microbiological wastewater treatment. Now, when economic reasons do no longer limit the application of MBR to industrial and municipal wastewater (WW) treatment [38] and that new requirements are being set for the treatment of WW, MBR treatment may become a key technique in all future scenarios that consider the direct or indirect reuse of wastewaters. This is due to two characteristics of MBRs, (a) the low sludge load in terms of BOD that can be expected to force bacteria to mineralise also poorly degradable organic compounds and (b) the high sludge age that gives the bacteria time to adapt to these substances $[39,40]$.

However, although many articles have reported the application of MBR for the treatment of urban and industrial wastewaters, up to our knowledge there are only few papers reporting on the behaviour of emerging contaminants during the MBR treatment, and all of them dealt with nonylphenolic compounds.

Using the MBR unit that comprises of three bioreactors and an external ultrafiltration unit followed by GAC adsorption, Witgens et al. [41] reported on the removal of more than $90 \%$ of NP in wastewater from a dumpsite leachate plant. Laboratory set of nanofiltration membranes resulted in retention of more than $70 \%$ of NP and this process was regarded as an alternative option for the final treatment of MBR effluent. 
Li et al. [42] used GC-MS and LC-MS-MS to assess the elimination efficiency in membrane-assisted biological WWTP. The results showed that compared to conventional WWTP membrane assisted biological treatment with biomass concentrations of about $20 \mathrm{~g} / \mathrm{l}$ could only improve elimination efficiency of NPEOs (and other ionic and non-ionic surfactants), but could not stop entirely the discharge with the permeates.

\subsection{Treatment by advanced oxidation processes (AOP)}

The AOP processes, using the combination of ozone with other oxidant agents (UV radiation, hydrogen peroxide, $\mathrm{TiO}_{2}$ ) have been studied to enhance the degradation of polar pharmaceuticals $[43,44,45]$ and NPEOs metabolites [46]. Ternes et al. [45] used a pilot plant for ozonation and UV disinfection of effluents form a German municipal WWTP containing antibiotics, betablockers, antiphlogistics, lipid regulator metabolites, musk fragrances and iodinated X-ray contrast media. By applying 10-15 mg/l ozone (contact time $18 \mathrm{~min}$ ) all the pharmaceuticals investigated were no longer detected. Exception was the ionic iodinated X-ray contrast compounds that exhibited removal efficiencies of not higher than $14 \%$.

In another study [44] the ozonation has been demonstrated to be a suitable tool for carbamazepine abatment even at the process conditions usually adopted in drinking water facilities. However, in spite of good primary elimination, a low degree of mineralization was observed and total carbon balance results lacking even for prolonged ozonation thus indicative the presence of some non-identified degradation products.

However, the degradation efficiency of an AOP is limited by the radical scavenging capacity of the matrix of the treated water. Thus, for a sufficient degradation of the 
pharmaceuticals ( $>90 \%$ ) from wastewater the ozone concentration has to be equal to the dissolved organic carbon (DOC) value [43], which means that economic considerations have to prove the feasibility of the process for wastewater treatment.

Recently, using a lab-scale reactor, Ike et al. [46] determined that the effectiveness of ozone treatment in the degradation of NPEO metabolites follows the order: $\mathrm{NPE}_{1} \mathrm{C}>>\mathrm{NP}>\mathrm{NP}_{1} \mathrm{EO}$. Acidic metabolites were completely degraded within 4-6 min (initial concentration was between 0.4 and $1.0 \mathrm{mg} / \mathrm{l}$ ), NP concentration reduced $75-80 \%$ in 6 min, while only 25 to $50 \%$ of $\mathrm{NP}_{1} \mathrm{EO}$ was eliminated in the same time.

\section{Elimination by treatment processes at drinking water treatment plants}

The occurrence of organic micro-contaminants in raw water and their removal in the course of drinking water production and possible formation of disinfection by-products are key issues in relation to the quality of drinking water supplies. Although, substances covered by this review are currently not regulated in drinking water, precautionary principles should be employed, and the removal of all organic micro-contaminants should be as high as possible. However, several studies showed that the removal of polar emerging contaminants during the drinking water treatment is not complete.

The elimination of selected pharmaceuticals (clofibric acid, diclofenac, carbamezapine, bezafibrate) during drinking water treatment processes was investigated at lab and pilot scale and in real waterworks in Germany [47]. Sand filtration under aerobic and anoxic conditions, as well as flocculation using iron(III)chloride exhibited no significant elimination of the target pharmaceuticals, while ozonation was quite effective in 
eliminating these polar compounds. Diclofenac and carbamezapine were reduced by more than $90 \%$, bezafibrate was eliminated by $50 \%$, while clofibric acid was stable even at high ozone doze. Filtration with granular activated carbon (GAC), under waterworks conditions was very effective in removing pharmaceuticals. Exception was clofibric acid which was less prone to adsorption.

The behaviour of polar alkylphenolic compounds during processing of contaminated water in waterworks and their possible occurrence in treated water has been was rarely the scope of interest and there are hardly any data available for drinking water. The elimination of neutral and acidic nonylphenolic compounds and their brominated and chlorinated derivatives, during drinking water treatment process at the waterworks that supply drinking water to city of Barcelona (Spain) was investigated utilizing a highly sensitive LC-MS-MS method [48]. The concentration of total nonylphenolic compounds: $\operatorname{NPEC}\left(n_{\mathrm{EO}}=0-1\right), \operatorname{NPEO}\left(n_{\mathrm{EO}}=1-2\right)$ and NP; in raw water (the Llobregat river) entering waterworks ranged from 8.3 to $21.6 \mu \mathrm{g} / \mathrm{L}$, with $\mathrm{NPE}_{2} \mathrm{C}$ being the most abundant compound. Prechlorination reduced the concentration of short-ethoxy chain NPECs and NPEOs by about $25-35 \%$, and of NP by almost $90 \%$. However, this reduction of concentrations was partially due to their transformation to halogenated derivatives. After prechlorination halogenated nonylphenolic compounds represented approximately $13 \%$ of the total metabolite pool, of which $97 \%$ were in the form of brominated acidic metabolites. The efficiency of further treatment steps to eliminate nonylphenolic compounds (calculated for the sum of all short ethoxy chain metabolites including halogenated derivatives) was as follows: settling and flocculation followed by rapid sand filtration (7.3\%), ozonation (86.3 $\%)$, GAC filtration $(72.7 \%)$ and final disinfection with chlorine $(42.8 \%)$, resulting in overall elimination ranging from 96.2 to $99.1 \%$ (mean $97.9 \%$ for four sampling dates) as shown in Fig. 2. 


\section{Conclusions}

The application of advanced LC-MS and GC-MS technologies to environmental analysis has allowed the determination of a broader range of compounds and thus permitted more comprehensive assessment of environmental contaminants. Among the various compounds considered as emerging pollutants, acidic pharmaceuticals, surfactant degradates and acidic pesticides are of particular concern, both because of their ubiquity in the aquatic environment and potential impacts.

Elimination of these emerging contaminants during wastewater and drinking water treatment is not satisfactory; and an improved treatment and strict control of the treatment process have to be employed so that the removal of these micro-contaminants is as high as possible. Thus, in view of possible reuse of WWTP effluents, more research is needed to evaluate their behaviour and fate in the aquatic environment. Moreover, disinfection processes applied (either chlorination or ozonation) potentially shift the assessment of the risk of human consumption of the parent compound to its degradation products, which requires development of generic analytical protocols that will permit simultaneous determination of parent compounds and their metabolites.

\section{Acknowledgements}

The work has been supported by the EU Project P-THREE (EVK1-CT-200200116) and by the Spanish Ministerio de Ciencia y Tecnologia (PPQ2002-10945-E). M. Petrovic acknowledges the "Ramon y Cajal" contract from the Spanish MCyT. S.Gonzalez acknowledges the grant from the Spanish McyT (PPQ2001-1805-CO3-01).

\section{References}

(after tables and figures) 


\section{Figure captions}

Fig. 1. Components of a (partially) closed water cycle with indirect potable reuse

Fig. 2. Fate of nonylphenolic compounds during drinking water production. A) Total concentration of nonylphenolic compounds and their elimination during different treatment steps at waterworks Sant Joan Despì (Barcelona, Spain); B) Average composition (calculated on a molar basis) of nonylphenolic compounds in raw water; C) Average composition (calculated on a molar basis) of nonylphenolic compounds in prechlorinated water 
Table 1. Methods for the analysis of acidic pharmaceuticals in wastewaters

\begin{tabular}{|c|c|c|c|c|c|c|}
\hline Compounds & Extraction & Derivatization & $\begin{array}{l}\text { Chromatographic } \\
\text { method }\end{array}$ & Detection & $\begin{array}{c}\mathrm{LOD} \\
(\mathrm{ng} / \mathrm{L})\end{array}$ & Reference \\
\hline $\begin{array}{l}\text { Bezafibrate, diclofenac, ibuprofen, } \\
\text { gemfibrozil, carbamezapine }\end{array}$ & $\begin{array}{l}\text { Sequential SPE }(\mathrm{C} 18 \\
+ \text { polymeric sorbent })\end{array}$ & - & $\mathrm{LC}$ & MS & 2 & 49 \\
\hline $\begin{array}{l}\text { Salicylic acid, ibuprofen, ketoprofen, } \\
\text { naproxen, bezafibrate, diclofenac }\end{array}$ & $\begin{array}{l}\text { SPE (polymeric } \\
\text { sorbent) }\end{array}$ & - & $\mathrm{LC}$ & MS & $5-56$ & 5 \\
\hline $\begin{array}{l}\text { Bezafibrate, clofibric acid, diclofenac, } \\
\text { fenoprofen, gemfibrozil, ibuprofen, } \\
\text { inomethacin, ketoprofen, naproxen }\end{array}$ & SPE (C18) & - & $\mathrm{LC}$ & MS-MS & $5-20$ & 50 \\
\hline Bezafibrate, clofibric acid, ibuprofen & $\begin{array}{c}\text { SPE (MCX or } \\
\text { polymeric sorbent) }\end{array}$ & - & $\mathrm{LC}$ & MS-MS & $0.016-2.18$ & 51 \\
\hline $\begin{array}{l}\text { Ibuprofen, clofibric acid, ketoprofen, } \\
\text { naproxen, diclofenac }\end{array}$ & SPE (HLB) & diazomethane & $\mathrm{GC}$ & MS & $0.3-4.5$ & 52 \\
\hline $\begin{array}{l}\text { Clofibric acid, diclofenac, ibuprofen, } \\
\text { phenazone, propyphenazone }\end{array}$ & SPE (C18) & $\begin{array}{l}\text { Pentaflorobenzyl } \\
\text { bromide }\end{array}$ & $\mathrm{GC}$ & MS & $0.6-20$ & 53 \\
\hline Clofibric acid, naproxen, ibuprofen & $\begin{array}{l}\text { SPE (polar Empore } \\
\text { disk) }\end{array}$ & $\begin{array}{l}\text { BSTFA (bis } \\
\text { (trimethylsilyl)- } \\
\text { triflouroacetamide }\end{array}$ & $\mathrm{GC}$ & MS & $0.4-2.6$ & 54 \\
\hline $\begin{array}{l}\text { Ibuprofen, naproxen, ketoprofen, tolfenamic } \\
\text { acid, diclofenac, meclofenamic acid }\end{array}$ & SPE (HLB) & $\begin{array}{l}\text { MTBSTFA (N- } \\
\text { methyl-N-(tert- } \\
\text { butyldimethylsilyl) } \\
\text { trifluoroacetamide }\end{array}$ & $\mathrm{GC}$ & MS & 20 & 55 \\
\hline
\end{tabular}


Table 2. Quantitation and diagnostic ions $(\mathrm{m} / \mathrm{z})$ used for the LC-MS and GC-MS, and base peaks of precursor and product ions used for LC-MSMS analysis of acidic pharmaceuticals in wastewaters. Data compiled from references listed in Table 1.

\begin{tabular}{|c|c|c|c|c|c|c|}
\hline \multirow[t]{2}{*}{ Compound } & \multirow[t]{2}{*}{ Analytical method } & \multirow{2}{*}{$\begin{array}{l}\text { Ionization } \\
\text { mode }\end{array}$} & \multirow{2}{*}{$\begin{array}{l}\text { MS } \\
\text { SIM ions } \\
\end{array}$} & \multicolumn{3}{|l|}{ MS-MS } \\
\hline & & & & Precursor $(m / z)$ & Product $1(\mathrm{~m} / \mathrm{z})$ & Product $2(\mathrm{~m} / \mathrm{z})$ \\
\hline Ibuprofen & $\begin{array}{l}\text { LC-MS } \\
\text { LC-MS-MS } \\
\text { GC-MS }\end{array}$ & $\begin{array}{l}\text { NI } \\
\text { NI } \\
\text { Positive EI }\end{array}$ & $\begin{array}{l}205,159 \\
177,220^{\mathrm{a}} \\
161,343,386^{\mathrm{b}} \\
263,278,234^{\mathrm{c}}\end{array}$ & $205[\mathrm{M}-\mathrm{H}]^{-}$ & $161\left[\mathrm{M}-\mathrm{H}-\mathrm{CO}_{2}\right]^{-}$ & 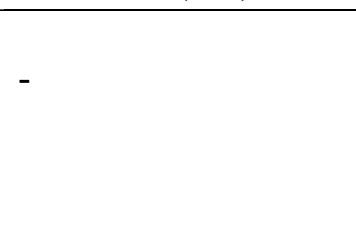 \\
\hline Diclofenac & $\begin{array}{l}\text { LC-MS } \\
\text { LC-MS-MS } \\
\text { GC-MS }\end{array}$ & $\begin{array}{l}\text { NI } \\
\text { NI } \\
\text { Positive EI }\end{array}$ & $\begin{array}{l}294,250,232 \\
214,309^{\mathrm{a}} \\
214,216,475^{\mathrm{b}} \\
352 / 354 / 356^{\mathrm{d}}\end{array}$ & $294[\mathrm{M}-\mathrm{H}]^{-}$ & $250\left[\mathrm{M}-\mathrm{H}-\mathrm{CO}_{2}\right]^{-}$ & - \\
\hline Clofibric acid & $\begin{array}{l}\text { LC-MS } \\
\text { LC-MS-MS } \\
\text { GC-MS }\end{array}$ & $\begin{array}{l}\text { NI } \\
\text { NI } \\
\text { Positive EI }\end{array}$ & $\begin{array}{l}128,228^{\mathrm{a}} \\
128,130,394^{\mathrm{b}} \\
128,143,286^{\mathrm{c}}\end{array}$ & $213[\mathrm{M}-\mathrm{H}]^{-}$ & $127\left[\mathrm{C}_{6} \mathrm{H}_{4} \mathrm{ClO}\right]^{-}$ & $85\left[\mathrm{C}_{4} \mathrm{H}_{5} \mathrm{O}_{2}\right]^{-}$ \\
\hline Gemfibrozil & $\begin{array}{l}\text { LC-MS } \\
\text { LC-MS-MS }\end{array}$ & $\begin{array}{l}\mathrm{NI} \\
\mathrm{NI}\end{array}$ & 249,121 & $249[\mathrm{M}-\mathrm{H}]^{-}$ & $121\left[\mathrm{M}-\mathrm{H}-\mathrm{C}_{7} \mathrm{H}_{12} \mathrm{O}_{2}\right]^{-}$ & \\
\hline Ketoprofen & $\begin{array}{l}\text { LC-MS } \\
\text { LC-MS-MS } \\
\text { GC-MS }\end{array}$ & $\begin{array}{l}\text { NI } \\
\text { NI } \\
\text { Positive EI }\end{array}$ & $\begin{array}{l}253,209,197 \\
209,268^{\mathrm{a}} \\
311^{\mathrm{d}}\end{array}$ & $253[\mathrm{M}-\mathrm{H}]^{-}$ & $209\left[\mathrm{M}-\mathrm{H}-\mathrm{CO}_{2}\right]^{-}$ & \\
\hline Naproxen & $\begin{array}{l}\text { LC-MS } \\
\text { LC-MS-MS } \\
\text { GC-MS }\end{array}$ & $\begin{array}{l}\text { NI } \\
\text { NI } \\
\text { Positive EI }\end{array}$ & $\begin{array}{l}229,185,173,170 \\
185,244^{\mathrm{a}} \\
243,302,185^{\mathrm{c}} \\
287^{\mathrm{d}}\end{array}$ & $229[\mathrm{M}-\mathrm{H}]^{-}$ & $185\left[\mathrm{M}-\mathrm{H}-\mathrm{CO}_{2}\right]^{-}$ & $170\left[\mathrm{M}-\mathrm{H}-\mathrm{C}_{2} \mathrm{H}_{3} \mathrm{O}_{2}\right]^{-}$ \\
\hline
\end{tabular}


Table 3. Elimination at WWTP (activated sludge treatment). Data complied from references $[12,28,37,52,55,56,57,58]$

\begin{tabular}{|c|c|c|c|c|}
\hline Compound & $\begin{array}{l}\text { Average } \\
\text { elimination } \\
(\%)^{\mathrm{a}}\end{array}$ & $\begin{array}{c}\text { Effluent } \\
\text { concentrations } \\
(\mu \mathrm{g} / \mathrm{L})\end{array}$ & $\begin{array}{l}\text { Main degradation } \\
\text { products }\end{array}$ & Observation \\
\hline \multicolumn{5}{|l|}{ Non ionic surfactants } \\
\hline Alkylphenol ethoxylates & $90-99$ & $<0.1-350$ & APEC, CAPEC, AP & $\begin{array}{c}\text { Primary degradation fast; ultimate degradation less } \\
\text { than } 40 \% \text {, metabolites potential endocrine } \\
\text { disruptors }\end{array}$ \\
\hline \multicolumn{5}{|l|}{ Pharmaceuticals } \\
\hline Ibuprofen & $65-90$ & $0.37-0.60(3.4)^{b}$ & & \\
\hline Diclofenac & $69-75$ & $0.06-0.81(2.1)$ & & Rapid photodegradation \\
\hline Clofibric Acid & $34-51$ & $0.12-0.36(1.6)$ & & Degradation product of lipid regulating agents \\
\hline Benzafibrate & 83 & $1.1-2.2(4.6)$ & & \\
\hline Naproxen & $45-66$ & $0.27-0.61(2.6)$ & & \\
\hline Ketoprofen & 69 & $0.02-0.38(0.87)$ & & \\
\hline Gemfibrozil & $46-69$ & $0.31-0.40(1.9)$ & & \\
\hline Carbamazepine & 7 & $0.30-2.1(6.3)$ & & Low removal rate \\
\hline \multicolumn{5}{|l|}{ Antiseptics } \\
\hline Triclosan & $44-92$ & $0.070-0.650$ & Methyl triclosan & Possible photodegradation \\
\hline \multicolumn{5}{|l|}{ Pesticides } \\
\hline Mecoprop and MCPA & - & $20-400$ & 2-methyl-4-Cl-phenol & Application period (mid-March until mid-May) \\
\hline $2,4-\mathrm{D}$ & - & $<20$ & 2,4-dichlorphenol & \\
\hline $2,4,5-\mathrm{T}$ & - & $<20$ & 2,4-D ; 2,4-dichlorphenol & \\
\hline
\end{tabular}

${ }^{a}$ Primary elimination of the parent compound

${ }^{\mathrm{b}}$ Range of average values detected (in parenthesis: maximum concentration detected) 


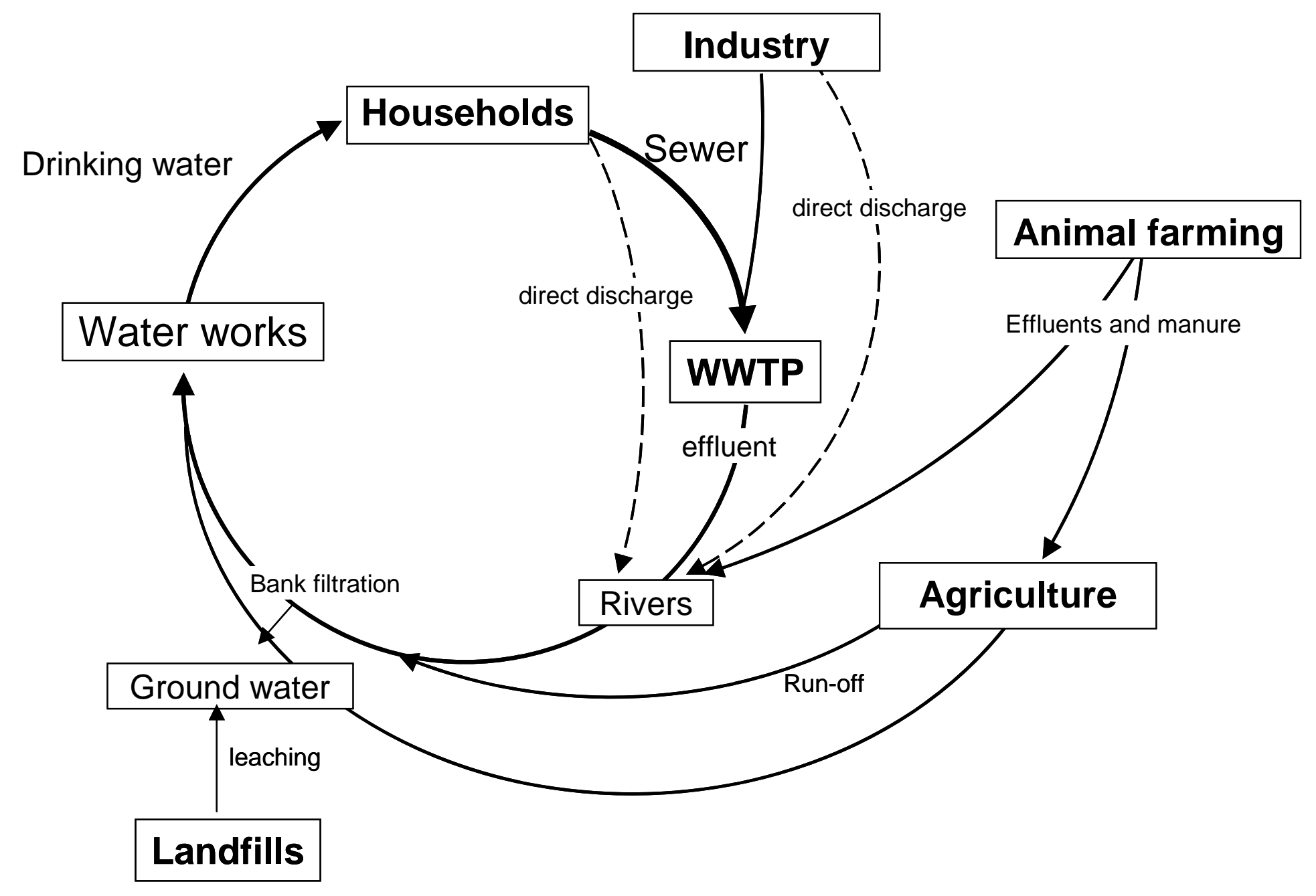


A)

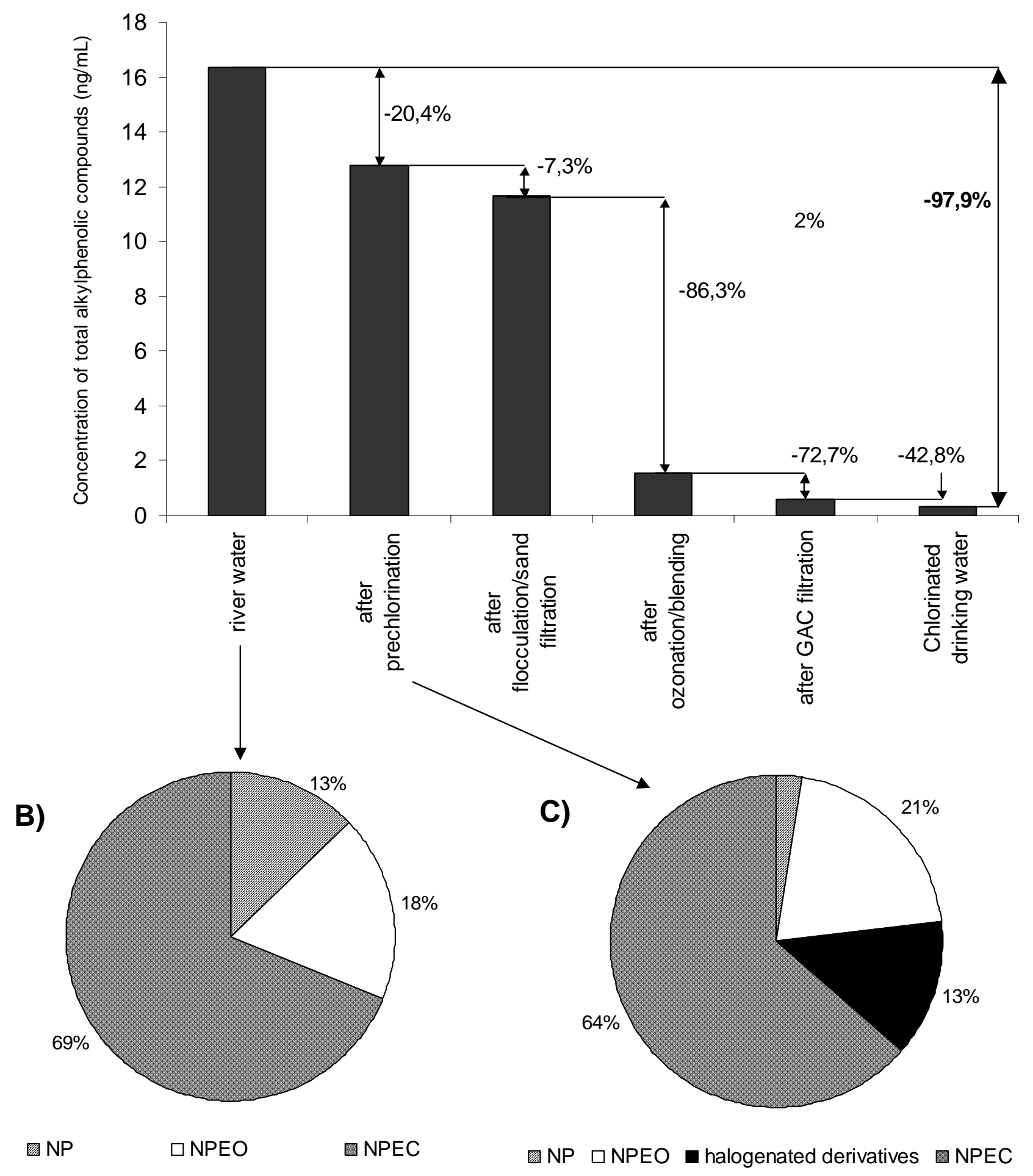


[1] C.G. Daughton A.T. Ternes; Environ. Health Perspect 107 (1999) 907.

[2] T. P. Knepper, F. Sacher, F.T. Lange, H.J. Brauch, F. Karrenbrock, O. Roeden, K Linder, Waste Manag. 19 (1999) 77.

[3] I. Janssens, T. Tanghe, W. Verstraete, Wat. Sci. Technol. 35 (1997) 12.

[4] T.A. Ternes, Trends Anal. Chem., 20 (2001) 419.

[5] M. Farré, I. Ferrer, A. Ginebreda, M. Figueras, L. Olivella, L. Tirapu, M. Vilanova, D. Barceló, J. Chromatogr. A 938 (2001) 187.

[6] W.H. Ding, C.H. Liu, S.P. Yeh, . Chromatogr. A 896 (2000) 111.

[7] T. Henriksen, B. Svensmark, B. Lindhardt, R.K. Juhler, Chemosphere 44 (2001) 1531.

[8] O. Pozo, E. Pitarch, J.V. Sancho. F. Hernandez, J. Chromatogr. A 923 (2001) 75.

[9] R. Bossi, K.V. Vejrup, B.B. Morgensen, W.A.H. Asam, J. Chromatogr. A 957 (2002) 27.

[10] M. Takino, S. Daishima, T. Nakahara, Analyst, 126 (2001) 602.

[11] M. Graovac, M. Todorovic, M.I. Trtanj, M.M. Kopecni, J.J. Comor, J. Chromatogr. A, 705 (1995) 313.

[12] A. Lindström, I.J. Buerge, T. Poiger, P.A. Bergqvist, M.D. Müller, H.R. Buser, Environ. Sci. Technol., 36 (2002) 2322.

[13] D.C. McAvoy, B. Schatowitz, M. Jacob, A. Hauk, W.S. Eckhoff, Environ. Toxicol. Chem., 21( 2002) 1323.

[14] A. Agüera, A.R. Fernandez-Alba, L. Piedra, M. Mezcua, M.J. Gomez, Anal. Chim Acta 480 (2003) 193.

[15] M. Petrovic, D. Barcelo, J. Mass Spectrom., 36 (2001) 1173.

[16] M.Petrovic, E. Eljarrat, M Lopez de Alda, D. Barceló, J. Chromatogr. A. 974 (2002) 23.

[17] M. Petrovic, A. Diaz, F. Ventura, D. Barcelo, Anal. Chem. 73 (2001) 5886.

[18] A. Di Corcia, J. Chromatogr. A, 794 (1998) 165.

[19] N. Jonkers, T.P. Knepper and P. de Voogt, Environ. Sci. Technol., 35 (2001) 335.

[20] A. Di Corcia, A. Constantino, C. Crescenzi, E. Marinoni, R. Samperi, Environ. Sci. Technol., 32 (1998) 2401.

[21] M. Petrovic, A. Diaz, F. Ventura, D. Barcelo, J. Am. Soc. Mass Spectrom. 14 (2003) 516.

[22] C. Hao, T.R. Croley, R.E. March, B.G. Koenig, C.D. Metcalfe, J. Mass Spectrom., 35 (2000) 818.

[23] W.H. Ding, C.T. Chen, J. Chromatogr. A, 862 (1999) 113.

[24] M. Ahel, T. Conrad, W. Giger, Environ. Sci. Technol., 21 (1987) 697.

[25] E. Stephanou, M. Reinhard, H.A. Ball, Biomed. Environ. Mass Spectrom., 15 (1988) 275.

[26] J.A. Field, R.L. Reed, Environ. Sci. Technol., 30 (1996) 3544.

[27] C. Tixier, H.P. Singer, S. Öllers, S.R. Müller, Environ. Sci. Technol. 37 (2003) 1061.

[28] T. A. Ternes, Wat. Research. 32 (1998), 3245.

[29] H.J. Stan, M. Linkerhänger, Vom Wasser 83 (1994) 57.

[30] T. Heberer, H.J. Stand, Von Wasser 86 (1996) 19.

[31] A.M. García-Campaña, J-J Aarón, J.M. Bosque-Sendra, Talanta 55 (2001)531.

[32] A.C. Gerecke, M.Schärer, H P. Singer, S. R. Müller, R.P. Schwarzenbach, M. Sägesser, U. Ochsenbein, G. Popow, Chemosphere 48 (2002) 307. 
[33] L. Nitscheke, A. Wilk, W. Schüssler, G. Metzner, G.Lind, Chemosphere 39 (1999) 2313.

[34] S. S. Mangat, P. Elefsiniotis, Wat. Res. 33(1999) 861.

[35] M. Ahel, W. Giger, M. Koch, Wat. Res. 28 (1994) 1131.

[36] A. Di Corcia, R. Cavallo, C. Crescenzi, M. Nazzari, Environ. Sci. Technol., 34 (2000) 3914.

[37] M. Petrovic, D. Barceló, Occurrence of surfactants in wastewater treatment plants, in T. Knepper, P. de Voogt, D. Barceló (Eds) Analysis and fate of surfactants in the aquatic environment, Elsevier, Amsterdam, 2003 (in press)

[38] M. Gander, B. Jefferson, S. Judd, Sep. Purif. Technol. 18 (2000) 119.

[39] T.A. Peters, R. Gunther, K. Vossenkaul, Filtr. Sep. 2000 (2000) 18.

[40] Côté et al., P. Côté, H. Buisson, C. Pound, G. Arakaki, Desalination 113 (1997) 189.

[41] T. Wintgens, M. Gellenkemper, T. Melin, Desalination 146 (2002) 387.

[42] H.Q. Li, F. Jiku, H.F. Schröder, J. Chromatogr. A 889 (2000) 155.

[43] C. Zwiener, F.H. Frimmel, Wat. Res. 34 (2000) 1881.

[44] R. Andreozzi, R. Marotta, G. Pinto, A. Pollio, Wat. Res. 36 (2002) 2869.

[45] T. A. Ternes, J. Stüber, N. Herrmann, D. McDowell, A. Ried, M. Kampmann, B. Teiser, Wat. Res. 37 (2003) 1976.

[46] M. Ike, M. Asano, F.D. Belkada, S. Tsunoi, M. Tanaka, M. Fujita, Wat. Sci. Technol. 46 (2002) 127.

[47] T. A. Ternes; Environ. Sci. Technol. 36 (2002) 3855.

[48] M. Petrovic, A. Diaz, F. Ventura and D. Barcelo, Environ. Sci. Technol (submitted)

[49] R. Loos, G. Hanke, S.J. Eisenreich, J. Environ. Monit. 5 (2003) 384.

[50] X.-S. Miao, B.G. Koenig, C.D. Metcalfe, J. Chromatogr. A 952 (2002) 139.

[51] D. Calamari, E. Zuccato, S. Castiglioni, R. Bagnati, R. Fanelli, Enviorn. Sci. Technol. 37 (2003) 1241.

[52] S. Öllers, H.P. Singer, P. Fässler, S.R. Müller, J. Chromatogr. A 911 (2001) 225.

[53] V. Koutsouba, Th. Heberer, B. Fuhrmann, K. Schmidt-Baumler, D. Tsipi, A. Hiskia, Chemosphere 51 (2003) 69.

[54] G.R. Boyd, H. Reemtsma, D.A. Grimm, S. Mitra, Sci. Total Environ. (2003) in press

[55] I. Rodriguez, J.B. Quintana, J. Carpintero, A.M. Carro, R.A. Lorenzo, R. Cela, J. Chromatogr. A 985 (2003) 265.

[56] B. Ferrari, N. Paxéus, R.Lo Giudice, A. Pollio, and J. Garric, Ecotoxicol. Environ. Safety, in press.

[57] M.Stumpf, T.A.Ternes, R- D Wilken, S.Vianna Rodrigues, W.Baumann. Sci.Total Environ. 225 (1999) 135.

[58] R.K.Juhler, S. R. Sorensen, L.Larsen. Wat. Res. 35 (2001) 1371. 